\title{
Modulation of the Reaction Mechanism via S/Mo: A \\ Rational Strategy for Large-Area $\mathrm{MoS}_{2}$ Growth
}

\author{
Jiangang Xu and Derek Ho*
}

Department of Materials Science and Engineering, City University of Hong Kong, Kowloon,

Hong Kong, China

Corresponding author: Derek Ho (derekho@ cityu.edu.hk) 


\section{Heterogeneous-only experiment design}

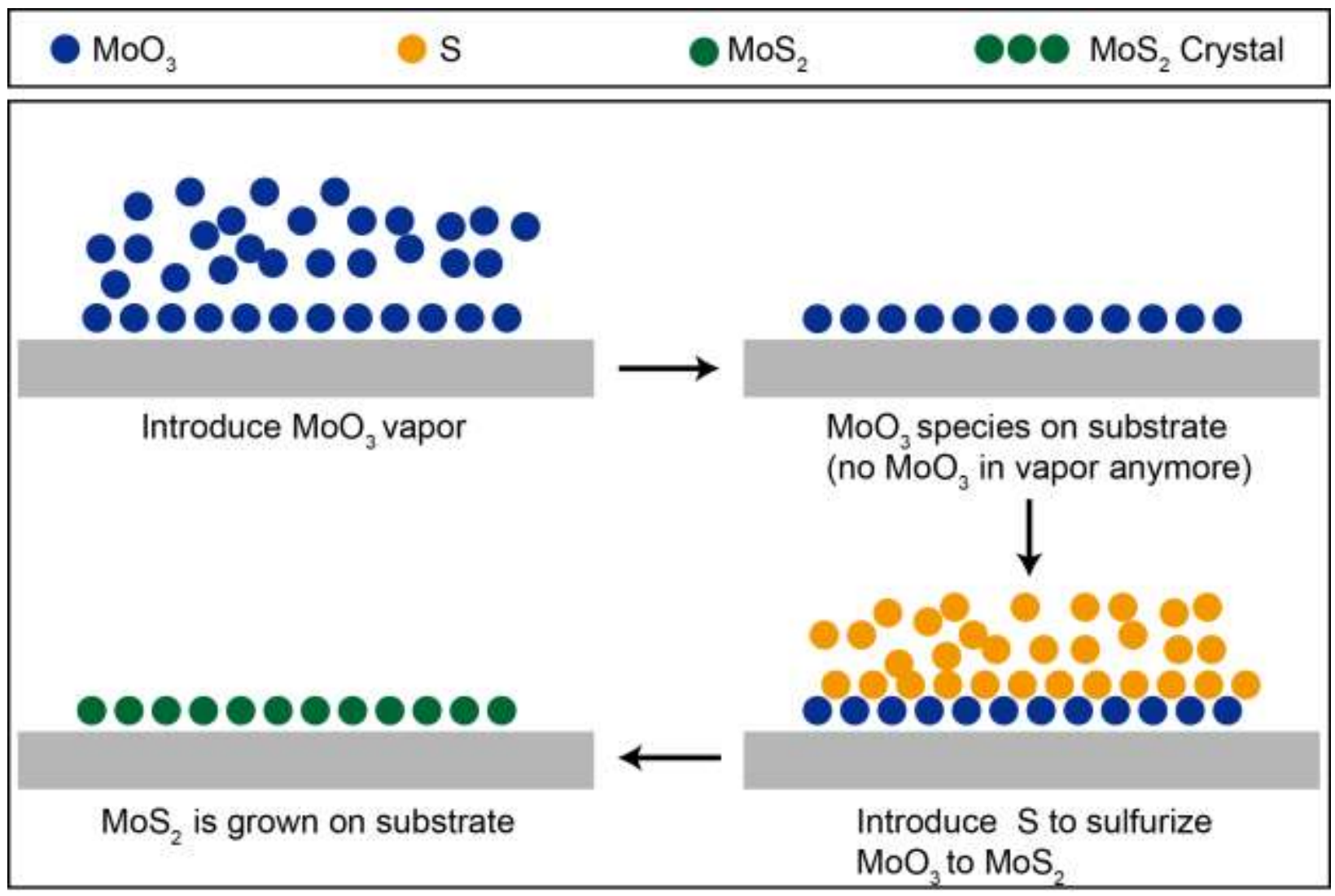

Figure S1. Schematic the (only) heterogeneous reaction.
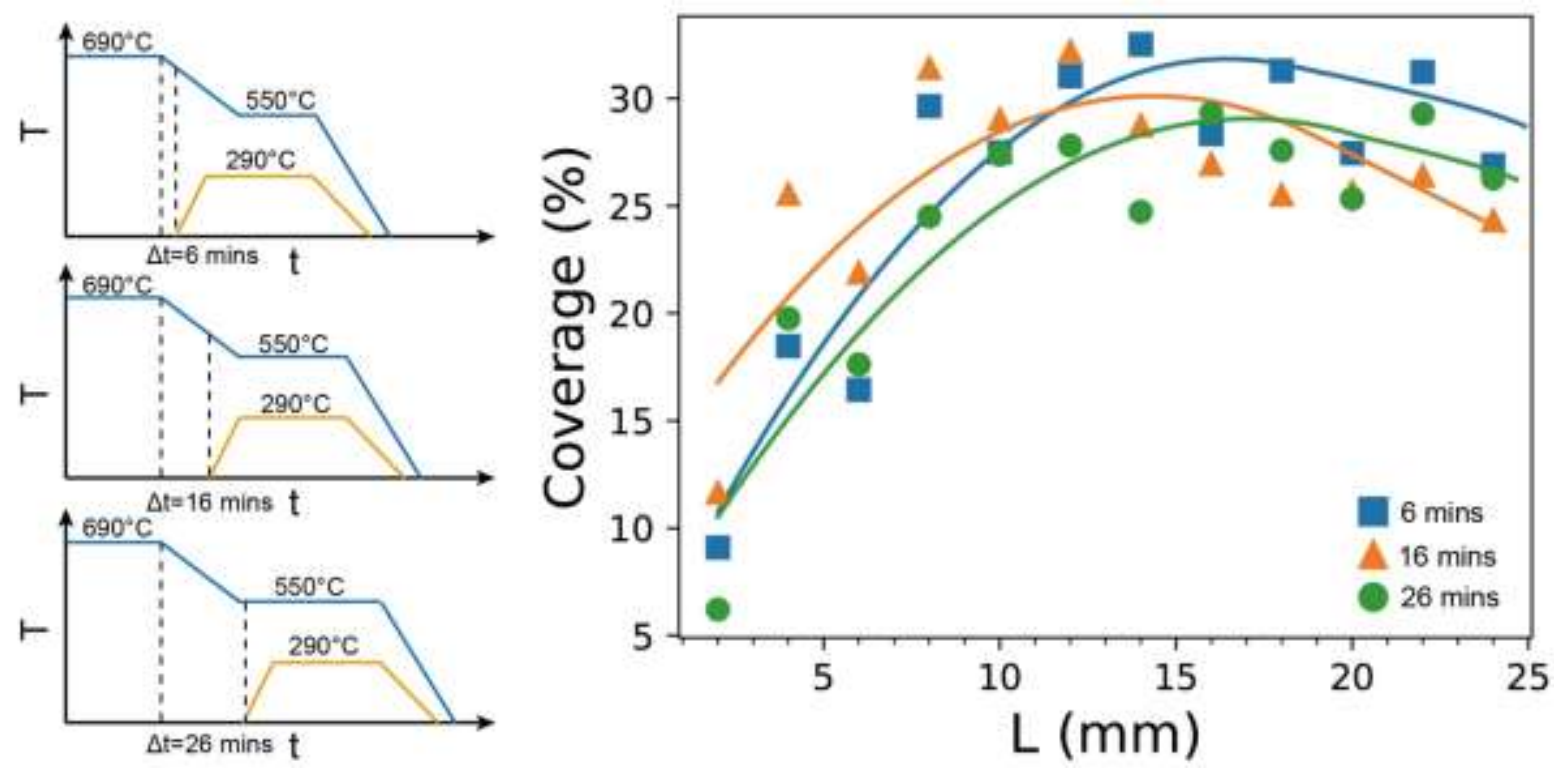
Figure S2. Left panels: schematic illustration of the temperature profile as a function of time. Blue and Orange for the temperature of Zone 2 and Zone 1 in the CVD system, respectively. The time interval $(\Delta t)$ between the introduction of $\mathrm{MoO}_{3}$ and $\mathrm{S}$ increases from 6 mins to 26 mins from top to bottom panel. Right panel: substrate coverage as a function of $\mathrm{L}$ across different $\Delta t$.

In the heterogeneous-only experiment, the adsorbed Mo species could re-evaporate from the substrate, contributing Mo vapor, thus leading to a homogeneous reaction. To verify the experiment is indeed heterogeneous-only, we have estimated the lifetime of the absorbed Mo species $(\tau)$ through studying the substrate coverage of $\mathrm{MoS}_{2}$ crystal as a function of the time interval $(\Delta t)$ between the introduction of $\mathrm{MoO}_{3}$ and $\mathrm{S}$, as schematically illustrated in the left panels of Figure S2. Lifetime here refers to the average time the adsorbed Mo species spend on the substrate before re-evaporating from the substrate. If $\tau$ is short compared with the growth time, it is expected that most of the adsorbed Mo species would re-evaporate before having a chance to react with $\mathrm{S}$, thus would result in less $\mathrm{MoS}_{2}$ on the substrate, i.e., smaller substrate coverage. However, we found that, by tuning the interval $(\Delta t)$ from 6 to 26 mins, the substrate coverage as a function of L remains nearly the same, as shown in the right panel of Figure S2, which indicates that $\tau$ is at least comparable to the growth time. In other words, the re-evaporation rate of the adsorbed Mo species $(1 / \tau)$ is small, thus the reaction can be deemed as heterogeneous only. We suspect that the long $\tau$ may be a result of the adsorbed Mo species forming some bonds with the substrate, i.e., there might be strong interaction between the adsorbed Mo species and the substrate. In fact, a similar observation has been previously reported by Lee et al., ${ }^{1}$ where the interaction between the $\mathrm{SiO}_{2} / \mathrm{Si}$ and $\mathrm{MoS}_{2}$ leads to distinct X-ray absorption spectroscopy (XAS) and synchrotron X-ray photoelectron spectroscopy (XPS) spectra from that of a free-standing $\mathrm{MoS}_{2}$ 
monolayer. The interaction has also been reported by Ahn et al., ${ }^{2}$ where VASP was used to study the chemisorption of precursor on quartz substrate $(\alpha-\mathrm{Si}(001))$.
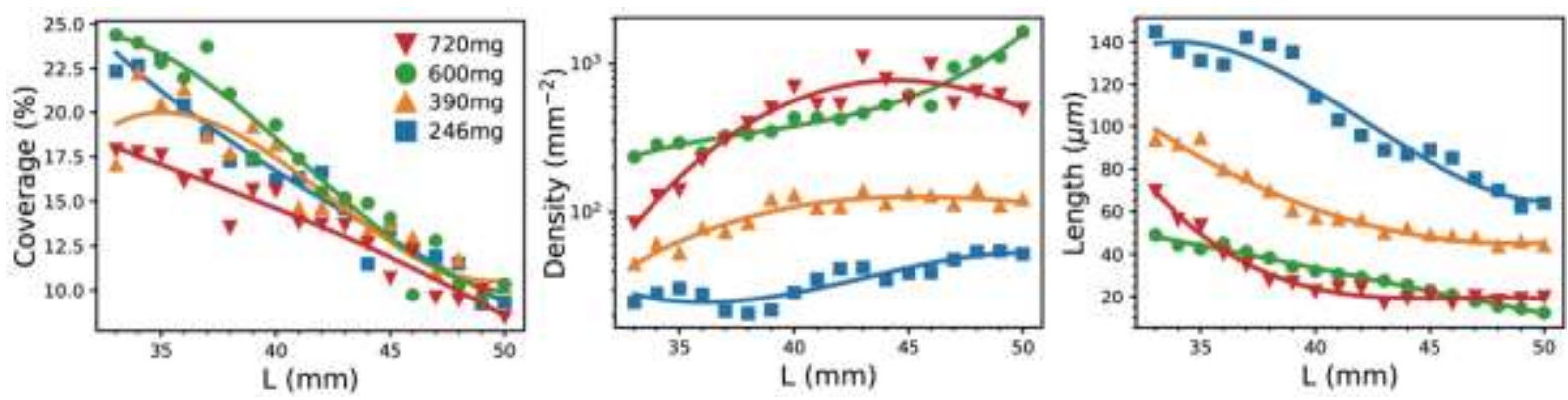

Figure S3. Effect of S/Mo on substrate coverage, nucleation density, and crystal edge length in the heterogeneous-only experiment.

To further demonstrate when the growth is in the homogeneous-only regime, S/Mo does not affect $\mathrm{MoS}_{2}$ critically, we have first introduced a fixed concentration of $\mathrm{MoO}_{3}$ species on the substrate, then introduced different concentrations of $\mathrm{S}$ across experimental runs, with the results shown in Figure S3. In order to study the effect of extremely high S/Mo, we have (i) focused on the area with $\mathrm{L}>30 \mathrm{~mm}$ ( $\mathrm{L}$ is the distance between the position on the substrate and the outlet of the Mo-tube, as defined in Figure 1a), where the S concentration is expected to be very high; (ii) the $\mathrm{S}$ consumption $\Delta \mathrm{S}$ is far greater than that in a typical experiment. As $\mathrm{L}$ is large, adsorbed $\mathrm{MoO}_{3}$ species concentration decreases significantly with L because of the radial diffusion of $\mathrm{MoO}_{3}$ vapor. As a result, the coverage also decreases with L. To evaluate the effect of S/Mo on the coverage, we focus on the coverage- $\mathrm{L}$ curves as a function of $\Delta \mathrm{S}$. Evidently, with increasing $\Delta \mathrm{S}$, coverageL curves shift little. In other words, in contrast to homogeneous reaction dominated regime, excessive S/Mo does not reduce the coverage in heterogeneous reaction dominated regime. From the density-L curves, evidently, the density increase $\sim 10$ times with $\Delta \mathrm{S}$, which is much smaller than that (more than 100 times as shown in Figure 2a) in homogeneous regime. The crystal edge 
length decreases $\sim 10$ times with $\Delta \mathrm{S}$, which is also much smaller than that in homogeneous reaction dominated regime, shown in Figure S3. The different effect of S/Mo on $\mathrm{MoS}_{2}$ growth in heterogeneous and homogeneous dominated regimes is significant, as it substantiates it is not S/Mo itself but the growth regime derived from S/Mo that critically affects the $\mathrm{MoS}_{2}$ growth behavior. In other words, the key to growing large-area $\mathrm{MoS}_{2}$ crystals using $\mathrm{MoO}_{3}$ and $\mathrm{S}$ as precursor is to promote heterogeneous reaction.

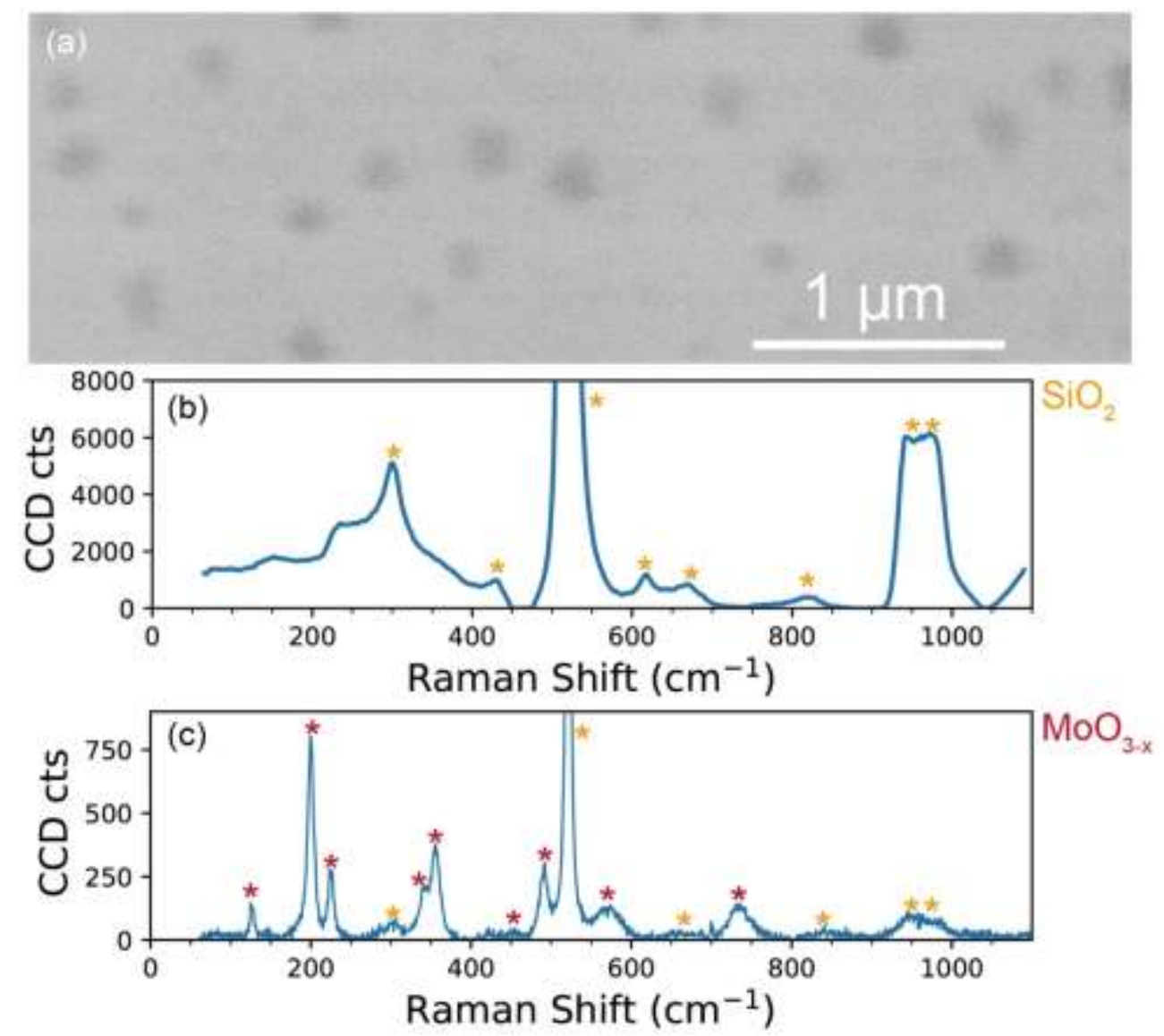

Figure S4. (a) SEM image of the deposited Mo species in heterogeneous-only experiment. (b), (c) Raman spectra of the $\mathrm{SiO}_{2} / \mathrm{Si}$ substrate and the deposited Mo species, respectively.

In a heterogeneous-only experiment, Mo species is first introduced onto the substrate, then $\mathrm{S}$ is introduced to react with the Mo adsorbed species, resulting $\mathrm{MoS}_{2}$ crystals on the substrate. It can be implied that there must be Mo species on the substrate, otherwise no $\mathrm{MoS}_{2}$ crystals could be 
grown. To support there is indeed adsorbed Mo species on the substrate, we have performed CVD experiment in which no $\mathrm{S}$ was introduced after $\mathrm{MoO}_{3}$ was deposited on the substrate. From the SEM image of the deposited substrate, some particles are evident (Figure S4a), which are the deposited Mo species. Due to the strong background signal from Si and the small concentration of adsorbed Mo species, SEM-EDX is not able to give any detectable signal. We resorted to Raman measurement instead, with the results shown in Figure S4b and S4c. In Figure S4b, the Raman spectrum of a bare $\mathrm{SiO}_{2} / \mathrm{Si}$ substrate is presented. In Figure $\mathrm{S} 4 \mathrm{c}$, the Raman spectrum of the adsorbed Mo species is presented. The peaks denoted by red star matches well with that of $\mathrm{MoO}_{\mathrm{x}},{ }^{1}$ demonstrating the existence of adsorbed Mo species. 


\section{Method to extract crystal density and edge length when crystals coalesce}

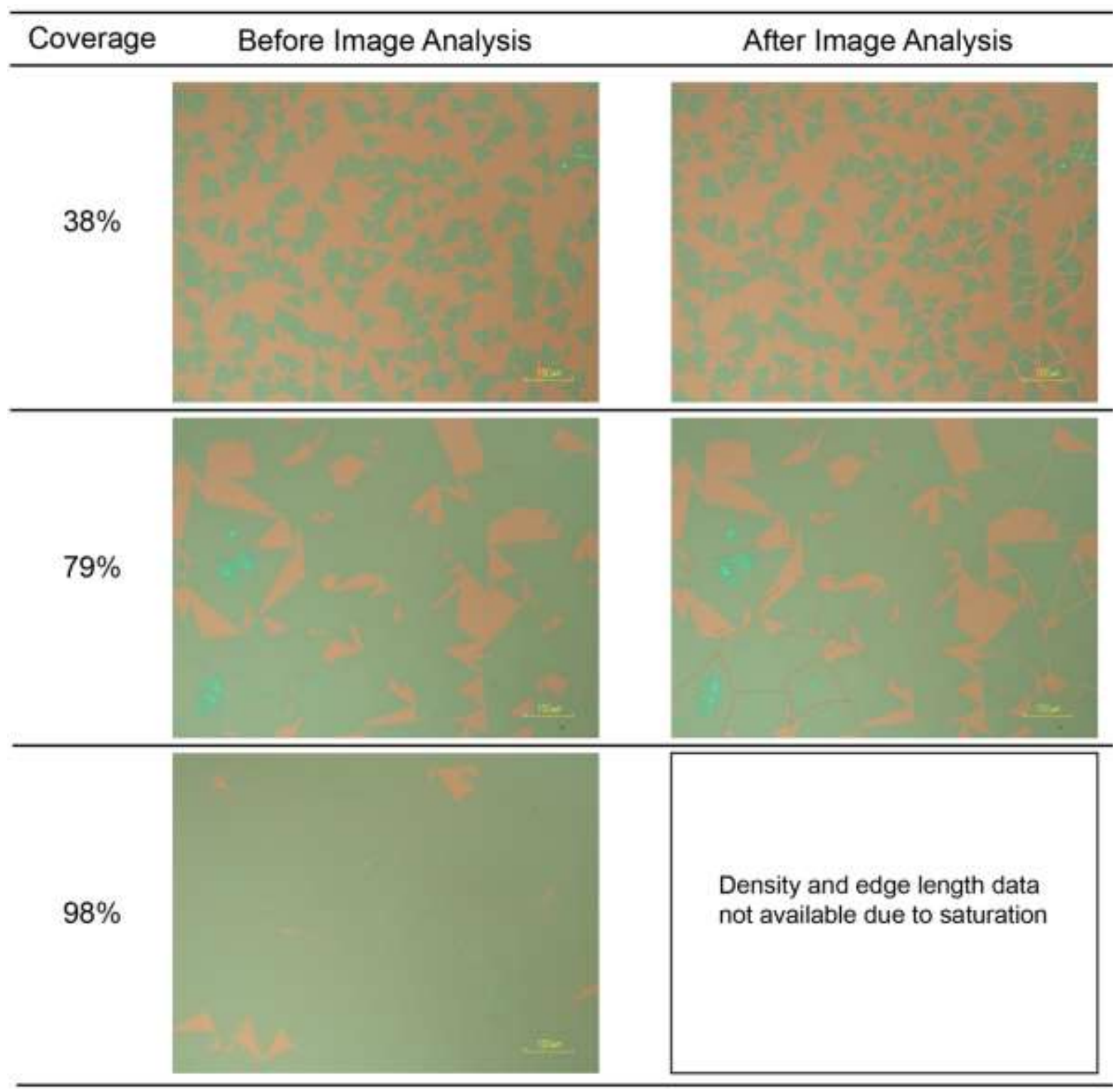

Figure S5. One example showing the method of extraction for nucleation density and crystal edge length when crystals coalesce.

For samples with large substrate coverage, the $\mathrm{MoS}_{2}$ crystals coalesced, thus ImageJ is not able to calculate the nucleation density and the crystal edge length correctly. To solve this problem, we manually separate the coalesced crystals by separating the coalesced part. Figure S5 show one 
example, which is from the sample with $\Delta \mathrm{S}=85 \mathrm{mg}$ in Figure 2. When the substrate coverage is too high (bottom row), boundaries between crystals are not recognizable, thus nucleation density and edge length are not reported in Figure 2 and Figure S7.

\section{Methods for accurate control of $\mathrm{MoO}_{3}$ evaporation}

Table S1. Methods for accurate control of $\mathrm{MoO}_{3}$ evaporation.

\begin{tabular}{|c|c|c|}
\hline Methods & Remarks & Ref \\
\hline $\begin{array}{l}\text { Dissolve } \mathrm{MoO}_{3} \text { in } \mathrm{NH}_{4} \mathrm{OH} \text {. Then } \mathrm{MoO}_{3} \\
\text { film is deposited on the substrate by spin } \\
\text { coating the } \mathrm{MoO}_{3} \text { solution }\end{array}$ & $\begin{array}{l}0.01 \mathrm{mg} \mathrm{MoO}_{3} \text { is consumed in } \\
\text { experiment }\end{array}$ & $\begin{array}{l}\text { 2017-Adv. } \\
\text { Mat. }^{2}\end{array}$ \\
\hline $\begin{array}{l}\text { Place } \mathrm{NiO} \text { foam between the substrate } \\
\text { and } \mathrm{MoO}_{3} \text { powder }\end{array}$ & $\begin{array}{l}\text { NiO foam acts as physical barrier } \\
\text { which regulates } \mathrm{MoO}_{3} \text { vapor }\end{array}$ & $\begin{array}{l}\text { 2018-ACS } \\
\mathrm{Nano}^{3}\end{array}$ \\
\hline $\begin{array}{l}\text { Seal } \mathrm{MoO}_{3} \text { in } \mathrm{SiO}_{2} \text { layer, which acts as } \\
\text { diffusion membrane to control the } \\
\text { amount of } \mathrm{MoO}_{3}\end{array}$ & Vapor-liquid-solid (VLS) growth & $\begin{array}{l}\text { 2020-Nat. } \\
\text { Com. }^{4}\end{array}$ \\
\hline Cover $\mathrm{MoO}_{3}$ powder with $\mathrm{SnO}_{2}$ & $\begin{array}{l}\text { Regulate the release of } \mathrm{MoO}_{3} \\
\text { vapor }\end{array}$ & $\begin{array}{l}\text { 2020-ACS } \\
\text { Nano }^{5}\end{array}$ \\
\hline $\begin{array}{l}\text { Control the carrier gas flow rate, } \\
\text { temperature and evaporation surface } \\
\text { area of } \mathrm{MoO}_{3} \text { powder }\end{array}$ & $\begin{array}{l}\mathrm{MoO}_{3} \text { consumption far less than } \\
1 \mathrm{mg}\end{array}$ & This work \\
\hline
\end{tabular}




\section{$4 \mathrm{~S}$ vapor concentration as a function of position}

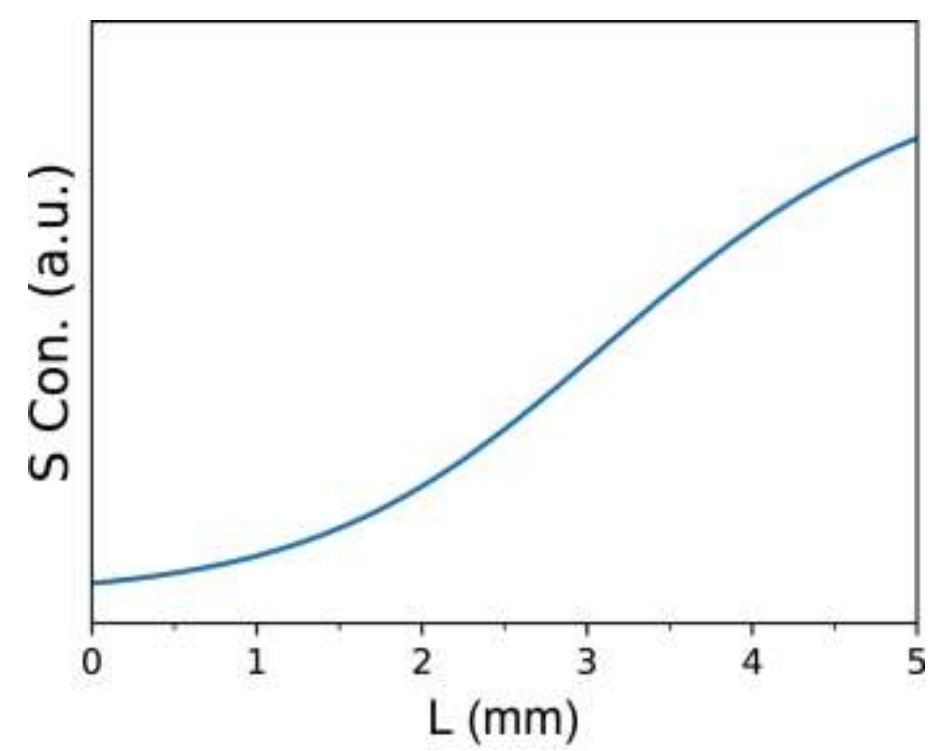

Figure S6. Calculated S concentration as a function of position.

To estimate the $\mathrm{S}$ concentration with respect to $\mathrm{L}$, and to verify that the $\mathrm{S}$ concentration indeed increases with $\mathrm{L}$, the convection-diffusion equation is employed, i.e. the $\mathrm{S}$ concentration is given by:

$$
\frac{\partial c}{\partial t}=\nabla \cdot(D \nabla \mathrm{c})-\nabla \cdot(\mathbf{v} c)
$$

where $\mathrm{D}$ is $\mathrm{S}$ diffusivity, $\mathbf{v}$ is the velocity of the $\mathrm{N}_{2}$ carrier gas. To qualitatively show the $\mathrm{S}$ concentration as a function of $\mathrm{L}$, the formulation is in $2 \mathrm{D}$. $\mathrm{D}$ typically has the value of $0.95 \mathrm{~cm}^{2} / \mathrm{s} .{ }^{6} \mathbf{v}$ is estimated to be $0.11 \mathrm{~cm} / \mathrm{s}$ for our experiment setup. Eq. S1 is solved in Fipy ${ }^{7}$ and the result is shown in Figure S6, which demonstrates that the S concentration increases with respect to L. The concentration of Mo decreases with $\mathrm{L}$ due to diffusion in the radial direction. Thus, S/Mo increases with $\mathrm{L}$. The increasing S/Mo with $\mathrm{L}$ is also confirmed by our experimental observation that $\mathrm{MoO}_{2}$ (insufficient $\mathrm{S}$ ) and $\mathrm{MoS}_{2}$ (enough $\mathrm{S}$ ) emerge sequentially on the substrate (Figure. S8h and S9a). 


\section{Crystal edge length data corresponding to Figure 2}
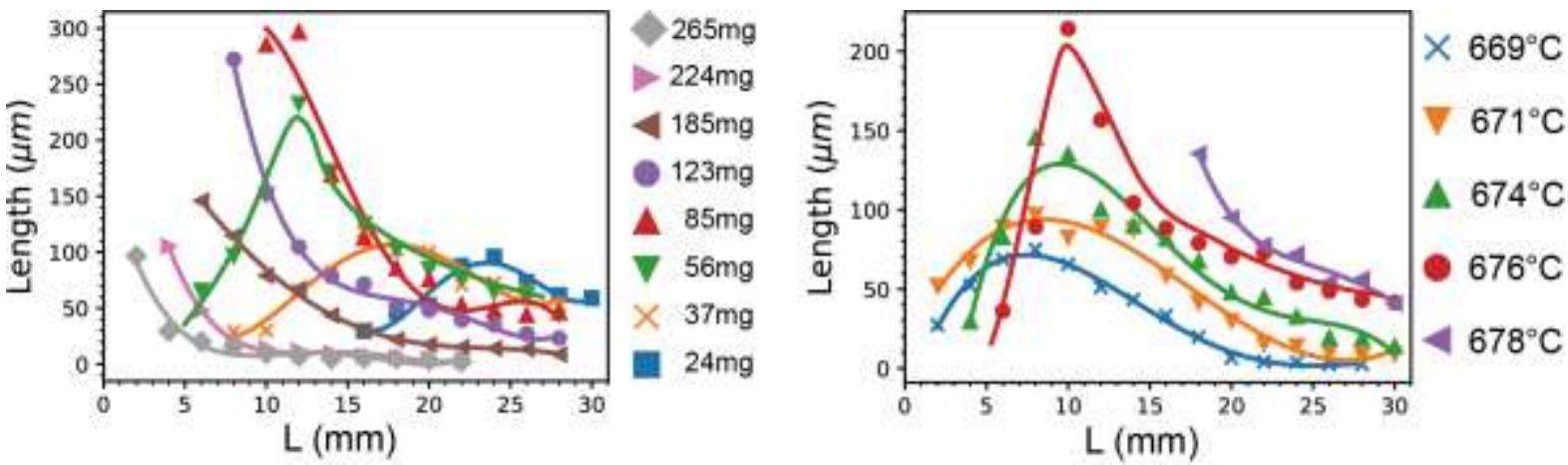

Figure S7. Results of crystal edge length corresponding to different S/Mo in Figure 2. 


\section{Optical microscopy (OM) images of samples studied in Figure 2}

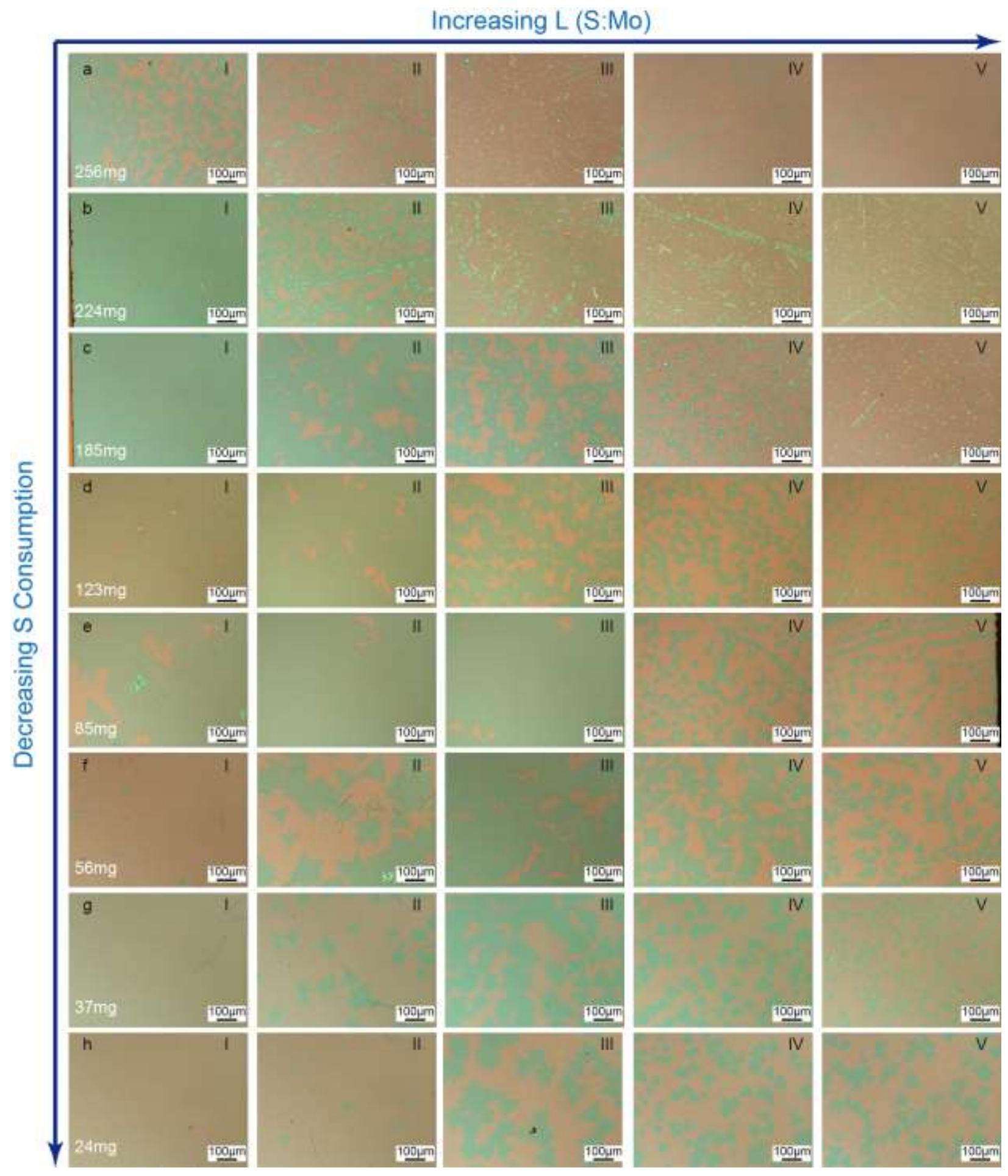

Figure S8. OM images of samples studied and presented in Figure $2 a$ and $2 b$, showing key trends. 
In rows $(\mathrm{e})-(\mathrm{h})$, the third column corresponds to the OM images near the peak position in Figure $2 b$.

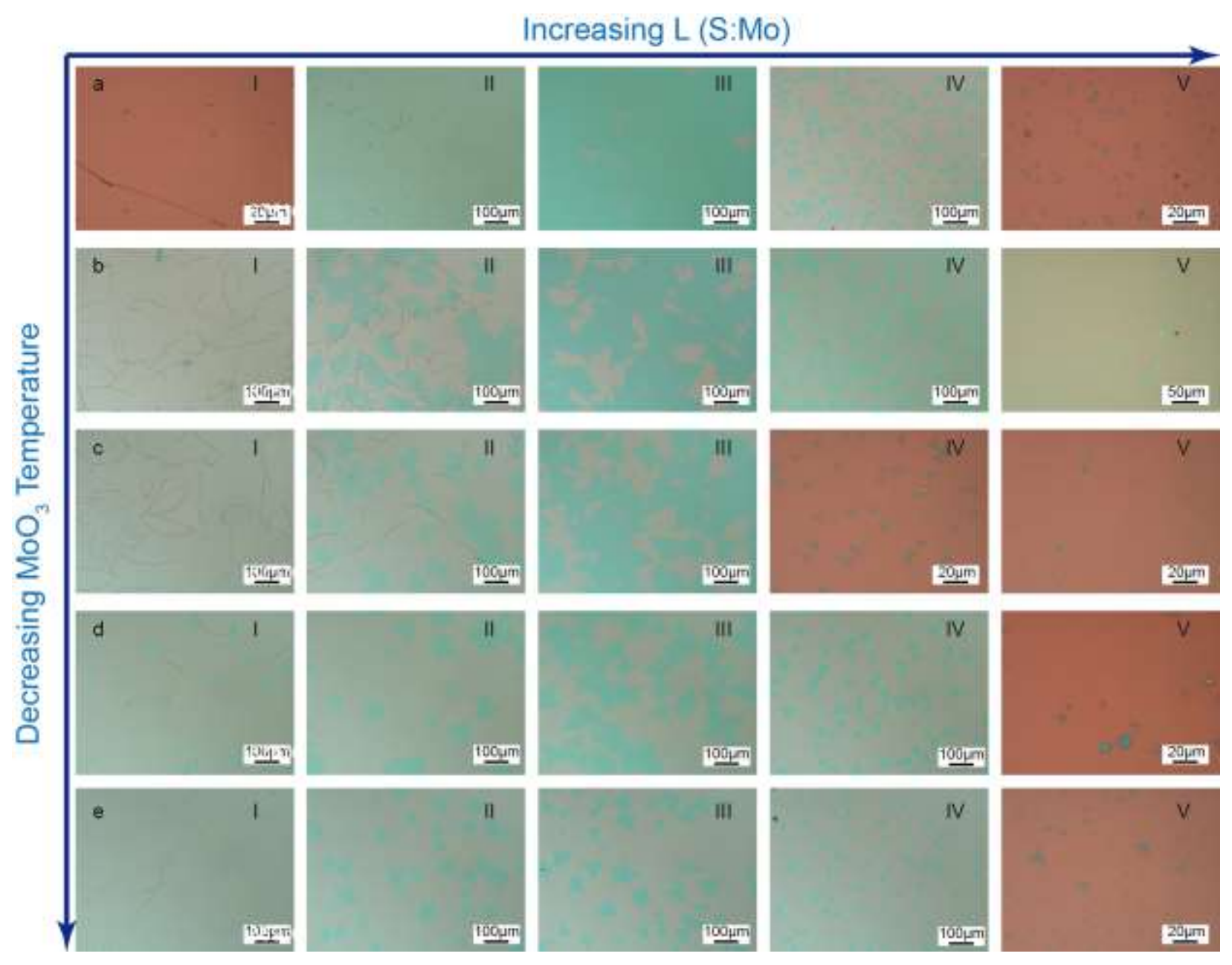

Figure S9. Characteristic OM images of samples studied in Figure $2 \mathrm{c}$ and $2 \mathrm{~d}$. The third column corresponds to the OM images near the peak position in Figure 2d.

\section{Estimation of energy released from chemical reaction}

The chemical reaction between $\mathrm{MoO}_{3}$ and $\mathrm{S}$ is

$$
\mathrm{MoO}_{3}(\mathrm{~g})+\frac{7}{4} \mathrm{~S}_{2}(\mathrm{~g})=\mathrm{MoS}_{2}(\mathrm{~s})+\frac{3}{2} \mathrm{SO}_{2}(\mathrm{~g})
$$

The enthalpy of formation $\Delta_{f} H^{0}$ for $\mathrm{MoO}_{3}, \mathrm{~S}_{2}, \mathrm{MoS}_{2}, \mathrm{SO}_{2}$ are $-346.44 \mathrm{~kJ} / \mathrm{mol}, 128.6 \mathrm{~kJ} / \mathrm{mol}$, $-276.14 \mathrm{~kJ} / \mathrm{mol}$, and $-296.84 \mathrm{~kJ} / \mathrm{mol}$, respectively. All the thermodynamics data may be found in 
the NIST Chemistry WebBook at https://webbook.nist.gov/. Therefore, the enthalpy change is $600.01 \mathrm{~kJ} / \mathrm{mol}$, which is indicative of an exothermic reaction. The released energy contributes to the kinetic energy of the products. Considering the product consists of 1 part $\mathrm{MoS}_{2}$ and 1.5 parts $\mathrm{SO}_{2}$, and by the conservation of energy and momentum over the reaction, the energy gained by one $\mathrm{MoS}_{2}$ molecule is

$$
\frac{600.01 \times 1000}{6 \times 10^{23}} \mathrm{~J} \times \frac{3}{8} \approx 2340 \mathrm{meV}
$$

To understand why a lower S/Mo favors heterogenous reaction, we hypothesize that, for a small $\mathrm{S} / \mathrm{Mo}$, the chemical reaction between $\mathrm{MoO}_{3}$ and $\mathrm{S}$ in vapor is not likely because of the positive change in Gibbs free energy. However, the reaction is likely on the substrate because the interaction between the substrate and the growing $\mathrm{MoS}_{2}$ crystal lowers the Gibbs free energy. ${ }^{8,9}$ 


\section{Evaluation of crystal homogeneity via Raman measurement}
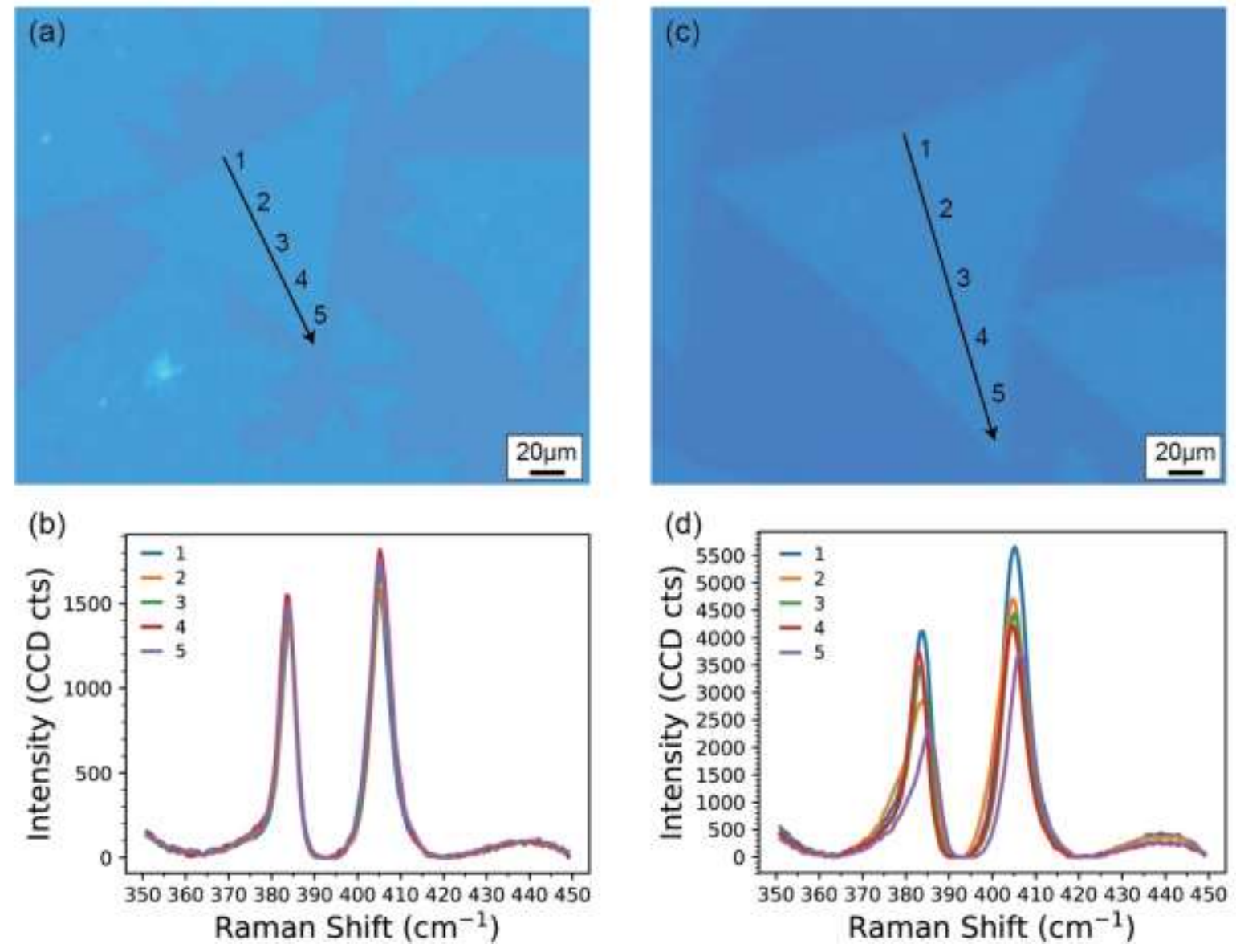

Figure S10. Raman spectra acquired across different positions on two $\mathrm{MoS}_{2}$ crystals.

To evaluate the homogeneity of the $\mathrm{MoS}_{2}$ crystals, we have acquired Raman spectra across different positions on single $\mathrm{MoS}_{2}$ crystals, with results presented in Figure S10. For the crystal in Figure S10a, both the intensity and the position of the two characteristic peaks vary slightly across the crystal (Figure S10b), indicating good homogeneity. However, for the crystal in Figure S10c, both the intensity and the position of the two characteristic peaks vary significantly (Figure S10d). We hypothesize the peak shift is due to strain release, as widely observed in previous studies. ${ }^{10-12}$ 


\section{Damaged $\mathrm{MoS}_{2}$ crystal grown at $850^{\circ} \mathrm{C}$}

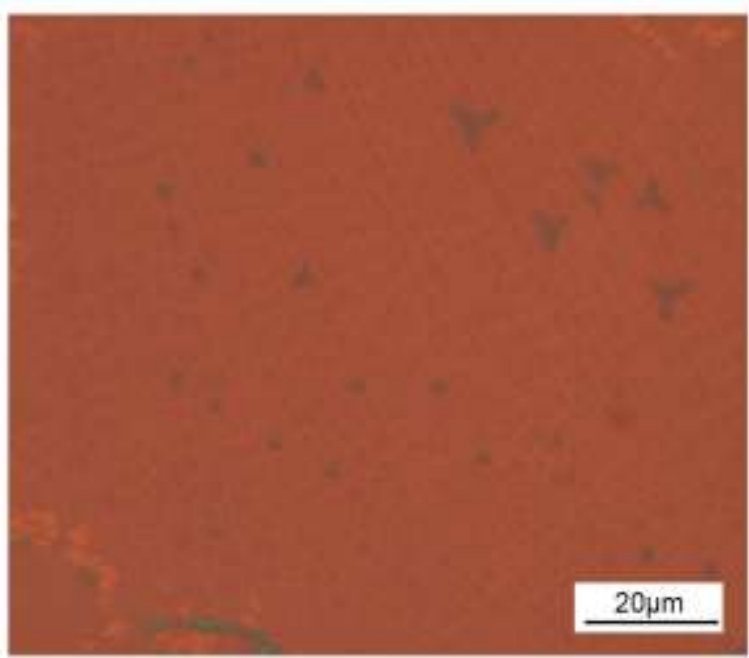

Figure S11. Cracks appear on the $\mathrm{MoS}_{2}$ crystal grown at $850^{\circ} \mathrm{C}$.

\section{Comparison of $\mathrm{MoS}_{2}$ crystal edge lengths}

Table S2. $\mathrm{MoS}_{2}$ crystal edge lengths from different growth methods.

\begin{tabular}{|c|c|c|c|c|}
\hline Precursors & Substrate & Length & Remarks & Ref. \\
\hline $\mathrm{MoO} 3$ and $\mathrm{S}$ & $\mathrm{SiO}_{2} / \mathrm{Si}$ & $320 \mu \mathrm{m}$ & $\mathrm{NA}$ & 2015-Sci. Rep. ${ }^{13}$ \\
\hline $\mathrm{MoO}_{3}$ and $\mathrm{S}$ & $\mathrm{SiO}_{2} / \mathrm{Si}$ & $305 \mu \mathrm{m}$ & $\begin{array}{l}\text { Reversed carrier } \\
\text { gas flow }\end{array}$ & 2016-Adv. Sci. ${ }^{14}$ \\
\hline $\mathrm{MoO}_{3}$ and $\mathrm{S}$ & $\mathrm{SiO}_{2} / \mathrm{Si}$ & $500 \mu \mathrm{m}$ & $0.01 \mathrm{mg} \mathrm{MoO}_{3}$ & 2017-Adv. Mat. ${ }^{2}$ \\
\hline $\mathrm{MoO}_{3}$ and $\mathrm{S}$ & $\mathrm{SiO}_{2} / \mathrm{Si}$ & $1.0 \mathrm{~mm}$ & $\mathrm{NaCl}$ promoted & 2018-Nature ${ }^{15}$ \\
\hline $\begin{array}{l}\mathrm{MoO}_{3} \text { with } \mathrm{Mo} \\
\text { foil and } \mathrm{S}\end{array}$ & Molten glass & $2.6 \mathrm{~mm}$ & $\begin{array}{l}\mathrm{Na} \text { (in molten } \\
\text { glass) promoted }\end{array}$ & $2017-J_{A C S}{ }^{16}$ \\
\hline Mo foil and S & Molten glass & $400 \mu \mathrm{m}$ & $\begin{array}{l}\mathrm{Na} \text { (in molten } \\
\text { glass) promoted }\end{array}$ & $\begin{array}{l}\text { 2018-Nat. } \\
\text { Com. }{ }^{17}\end{array}$ \\
\hline $\begin{array}{l}\left(\mathrm{NH}_{4}\right)_{2} \mathrm{MoO}_{4} \text { and } \\
\mathrm{S}\end{array}$ & Sapphire & $470 \mu \mathrm{m}$ & $\begin{array}{l}\text { Substrate treated } \\
\text { with } \mathrm{KOH}\end{array}$ & 2020-JACS ${ }^{18}$ \\
\hline $\mathrm{MoO}_{3}$ and $\mathrm{S}$ & $\mathrm{SiO}_{2} / \mathrm{Si}$ & $550 \mu \mathrm{m}$ & NA & This work \\
\hline
\end{tabular}




\section{More examples showing $\mathrm{MoS}_{2}$ crystals with larger edge length}
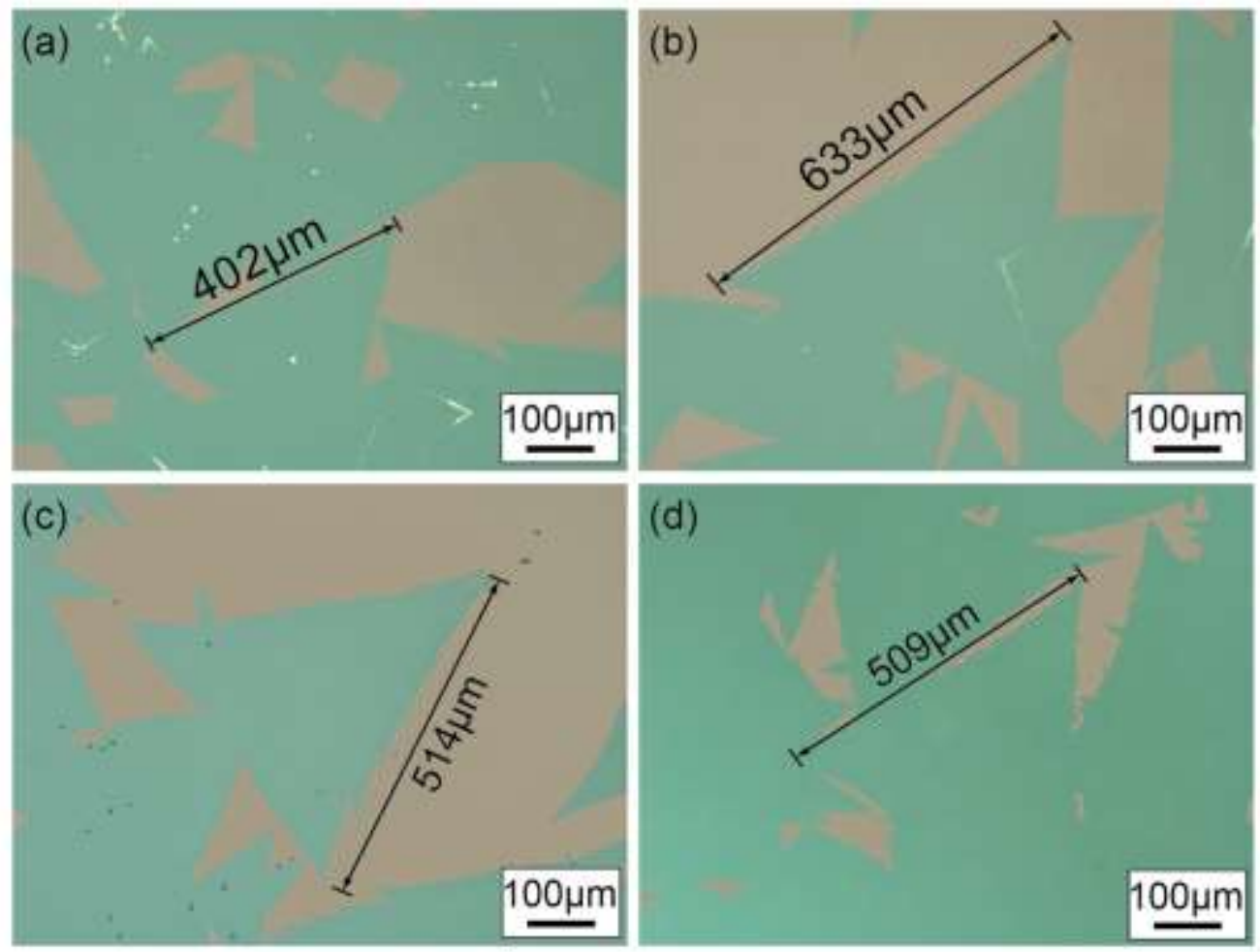

Figure S12. OM images of $\mathrm{MoS}_{2}$ crystals with edge length greater than $400 \mu \mathrm{m}$ from four different experiment runs, with a growth temperature of $780^{\circ} \mathrm{C}$.

To further demonstrate our strategy of utilizing S/Mo as a primary process parameter, we have maintained S/Mo at an optimal value and repeated growth at $780^{\circ} \mathrm{C}$ several times. As shown in Figure S12, large $\mathrm{MoS}_{2}$ crystals with edge length over $500 \mu \mathrm{m}$ were readily achieved. We also observed a small amount of thicker portions on the crystals, which might be due to homogeneous reaction condition at the very beginning or the cooling down period of growth, as in such period, growth condition is unstable. Nevertheless, during the growth period, reaction must have been heterogeneous reaction dominant. Otherwise, the crystal should not be able to grow large and should be full of dense crystals. Other strategies, for example, the reverse-flow strategy proposed 
by Zhang et al., ${ }^{19}$ may be employed to avoid the unstable growth period thus further improving the quality of the grown $\mathrm{MoS}_{2}$ crystals.

\section{References}

1. Camacho-López, M. A.; Escobar-Alarcón, L.; Picquart, M.; Arroyo, R.; Córdoba, G.; Haro-Poniatowski, E., Micro-Raman Study of the $\mathrm{m}-\mathrm{MoO}_{2}$ to $\alpha-\mathrm{MoO}_{3}$ Transformation Induced by CW-Laser Irradiation. Opt. Mater. 2011, 33, 480-484.

2. Lee, J.; Pak, S.; Giraud, P.; Lee, Y. W.; Cho, Y.; Hong, J.; Jang, A. R.; Chung, H. S.; Hong,

W. K.; Jeong, H. Y.; Shin, H. S.; Occhipinti, L. G.; Morris, S. M.; Cha, S.; Sohn, J. I.; Kim, J. M., Thermodynamically Stable Synthesis of Large-Scale and Highly Crystalline Transition Metal Dichalcogenide Monolayers and Their Unipolar n-n Heterojunction Devices. Adv. Mater. 2017, 29, 1702206.

3. Lim, Y.-F.; Priyadarshi, K.; Bussolotti, F.; Gogoi, P. K.; Cui, X.; Yang, M.; Pan, J.; Tong, S. W.; Wang, S.; Pennycook, S. J.; Goh, K. E. J.; Wee, A. T. S.; Wong, S. L.; Chi, D., Modification of Vapor Phase Concentrations in $\mathrm{MoS}_{2}$ Growth Using a Nio Foam Barrier. ACS Nano 2018, 12, 1339-1349.

4. Chang, M.-C.; Ho, P.-H.; Tseng, M.-F.; Lin, F.-Y.; Hou, C.-H.; Lin, I. K.; Wang, H.; Huang, P.-P.; Chiang, C.-H.; Yang, Y.-C.; Wang, I. T.; Du, H.-Y.; Wen, C.-Y.; Shyue, J.-J.; Chen, C.-W.; Chen, K.-H.; Chiu, P.-W.; Chen, L.-C., Fast Growth of Large-Grain and Continuous MoS 2 Films through a Self-Capping Vapor-Liquid-Solid Method. Nat. Commun. 2020, 11, 3682.

5. Shi, R.; He, P.; Cai, X.; Zhang, Z.; Wang, W.; Wang, J.; Feng, X.; Wu, Z.; Amini, A.; Wang, N.; Cheng, C., Oxide Inhibitor-Assisted Growth of Single-Layer Molybdenum 
Dichalcogenides $\left(\mathrm{MoX}_{2}, \mathrm{X}=\mathrm{S}, \mathrm{Se}, \mathrm{Te}\right)$ with Controllable Molybdenum Release. ACS Nano 2020, $14,7593-7601$.

6. Bird, R. B., Transport Phenomena. 2nd ed.; J. Wiley: New York, 2002.

7. Guyer, J. E.; Wheeler, D.; Warren, J. A., Fipy: Partial Differential Equations with Python. Comput. Sci. Eng. 2009, 11, 6-15.

8. Lee, M.; Kim, Y.; Mohamed, A. Y.; Lee, H.-K.; Ihm, K.; Kim, D. H.; Park, T. J.; Cho, D.Y., Direct Evidence of Electronic Interaction at the Atomic-Layer-Deposited $\mathrm{MoS}_{2}$ Monolayer/ $\mathrm{SiO}_{2}$ Interface. ACS Appl. Mater. Interfaces 2020, 12, 53852-53859.

9. Ahn, C.; Park, Y.; Shin, S.; Ahn, J.-G.; Song, I.; An, Y.; Jung, J.; Kim, C. S.; Kim, J. H.; Bang, J.; Kim, D.; Baik, J.; Lim, H., Growth of Monolayer and Multilayer MoS2 Films by Selection of Growth Mode: Two Pathways via Chemisorption and Physisorption of an Inorganic Molecular Precursor. ACS Appl. Mater. Interfaces 2021, 13, 6805-6812.

10. Ahn, G. H.; Amani, M.; Rasool, H.; Lien, D. H.; Mastandrea, J. P.; Ager, J. W.; Dubey, M.; Chrzan, D. C.; Minor, A. M.; Javey, A., Strain-Engineered Growth of Two-Dimensional Materials. Nat. Commun. 2017, 8, 608.

11. Feng, S.; Yang, R.; Jia, Z.; Xiang, J.; Wen, F.; Mu, C.; Nie, A.; Zhao, Z.; Xu, B.; Tao, C.; Tian, Y.; Liu, Z., Strain Release Induced Novel Fluorescence Variation in CVD-Grown Monolayer $\mathrm{WS}_{2}$ Crystals. ACS Appl. Mater. Interfaces 2017, 9, 34071-34077.

12. McCreary, K. M.; Hanbicki, A. T.; Singh, S.; Kawakami, R. K.; Jernigan, G. G.; Ishigami, M.; Ng, A.; Brintlinger, T. H.; Stroud, R. M.; Jonker, B. T., The Effect of Preparation Conditions on Raman and Photoluminescence of Monolayer $\mathrm{WS}_{2}$. Sci. Rep. 2016, 6, 35154. 
13. Lin, Z. Y.; Zhao, Y. D.; Zhou, C. J.; Zhong, R.; Wang, X. S.; Tsang, Y. H.; Chai, Y., Controllable Growth of Large-Size Crystalline $\mathrm{MoS}_{2}$ and Resist-Free Transfer Assisted with a $\mathrm{Cu}$ Thin Film. Sci. Rep. 2015, 5, 18596.

14. Chen, J.; Tang, W.; Tian, B.; Liu, B.; Zhao, X.; Liu, Y.; Ren, T.; Liu, W.; Geng, D.; Jeong, H. Y.; Shin, H. S.; Zhou, W.; Loh, K. P., Chemical Vapor Deposition of High-Quality Large-Sized $\mathrm{MoS}_{2}$ Crystals on Silicon Dioxide Substrates. Adv Sci 2016, 3, 1500033.

15. Zhou, J. D.; Lin, J. H.; Huang, X. W.; Zhou, Y.; Chen, Y.; Xia, J.; Wang, H.; Xie, Y.; Yu, H. M.; Lei, J. C.; Wu, D.; Liu, F. C.; Fu, Q. D.; Zeng, Q. S.; Hsu, C. H.; Yang, C. L.; Lu, L.; Yu, T.; Shen, Z. X.; Lin, H.; Yakobson, B. I.; Liu, Q.; Suenaga, K.; Liu, G. T.; Liu, Z., A Library of Atomically Thin Metal Chalcogenides. Nature 2018, 556, 355-359.

16. Chen, J.; Zhao, X.; Tan, S. J. R.; Xu, H.; Wu, B.; Liu, B.; Fu, D.; Fu, W.; Geng, D.; Liu, Y.; Liu, W.; Tang, W.; Li, L.; Zhou, W.; Sum, T. C.; Loh, K. P., Chemical Vapor Deposition of Large-Size Monolayer MoSe 2 Crystals on Molten Glass. J. Am. Chem. Soc. 2017, 139, 1073-1076.

17. Yang, P. F.; Zou, X. L.; Zhang, Z. P.; Hong, M.; Shi, J. P.; Chen, S. L.; Shu, J. P.; Zhao, L. Y.; Jiang, S. L.; Zhou, X. B.; Huan, Y. H.; Xie, C. Y.; Gao, P.; Chen, Q.; Zhang, Q.; Liu, Z. F.; Zhang, Y. F., Batch Production of 6-Inch Uniform Monolayer Molybdenum Disulfide Catalyzed by Sodium in Glass. Nat. Commun. 2018, 9, 979.

18. Zhu, J.; Li, W.; Huang, R.; Ma, L.; Sun, H.; Choi, J.-H.; Zhang, L.; Cui, Y.; Zou, G., OnePot Selective Epitaxial Growth of Large $\mathrm{WS}_{2} / \mathrm{MoS}_{2}$ Lateral and Vertical Heterostructures. J. Am. Chem. Soc. 2020, 142, 16276-16284. 
19. Zhang, Z.; Chen, P.; Duan, X.; Zang, K.; Luo, J.; Duan, X., Robust Epitaxial Growth of Two-Dimensional Heterostructures, Multiheterostructures, and Superlattices. Science 2017, 357 , 788-792. 